\title{
VIEWPOINTS
}

\section{One Health and Hansen's disease in Brazil}

\author{
Patrícia Deps $\oplus^{1 *}$, Patrícia S. Rosa²
}

1 Department of Social Medicine and Postgraduate Programme in Infectious Diseases, Federal University of Espírito Santo, Vitória, Espírito Santo, Brazil, 2 Division of Research and Education, Instituto Lauro de Souza Lima, Bauru, São Paulo, Brazil

* patricia.deps@ufes.br

\section{One Health and Hansen's disease}

The concept of One Health originated with the German pathologist Rudolf Virchow in the late 19 th century but has become a global movement only in the past 2 decades [1]. One Health recognizes that issues of human health and well-being cannot be addressed in isolation but must be considered in the context of equilibrium between all living things and the natural environment [2]. These aspects of people's health have become more important with human population growth, climate change, ecological pressures, and globalization [3].

Zoonoses present one of the most obvious One Health challenges [4]. In 1971, researchers in the United States of America reported that armadillos reproduce systemic and neurocutaneous forms of leprosy if inoculated with Mycobacterium leprae [5]. Natural infection of an armadillo of the species Dasypus novemcinctus was reported 6 years later, and sporadic autochthonous cases have since been identified in which the persons affected reported contact with armadillos but no other risk factors [6]. Hansen's disease is now officially recognized as a zoonosis in the USA, based on evidence of widespread natural infection of armadillos with $M$. leprae [7] and evidence of Hansen's disease arising from direct and indirect contact with wild armadillos [8,9].

In Brazil, almost 30,000 new cases of Hansen's disease are diagnosed each year, with some areas experiencing hyperendemicity ( $\geq 40$ cases/100,000 population per year) [10]. Brazil is within the range of several armadillo species which inhabit the Amazon, Atlantic Forest, and semiarid ecosystems [11]. Natural infection of wild armadillos by $M$. leprae has been reported across Brazil, equivalent to 1 in 10 animals being infected with the bacillus [12]. All armadillo species are protected in Brazil, and some are critically endangered [13], but their habitats are dwindling in size and disturbed by human activity, and illegal hunting to obtain meat for private consumption and commercial sale is widespread [11]. These activities result in frequent direct and indirect contact between humans and potentially infected armadillos [14], but zoonotic transmission of $M$. leprae is currently disregarded in Brazil as an issue for Hansen's disease control and prevention.

The suspicion that Hansen's disease might not only affect humans dates to the early 20th century when contagion through direct contact with a person infected by the recently discovered M. leprae bacillus had become the predominant belief. This gave rise to sanatoriums or "colonies" as a coordinated public health response. Nonetheless, at the Second International Leprosy Congress in 1909, it was suggested that M. leprae might also exist in the environment (soil and plants) and in animals [15].

The environmental hypothesis has been borne out by studies based on plants, soil, and water sampled in non-endemic and endemic countries [16], including viable M. leprae detected in soil near the homes of persons affected by Hansen's disease in India [17]. Natural infection of animals with $M$. leprae has been reported for several species [16], including 2 
recent chimpanzee cases in West Africa [18]. However, the primary focus on Hansen's disease as a zoonosis revolves around armadillos in the Americas.

Armadillos belong to the superorder of placental mammals, Xenarthra, inhabitants of the Americas for 60 million years [19]. Humans have inhabited the continent for around 13,000 years [20], and M. leprae was the last to arrive, probably with exploration and colonization from Europe and human trafficking from Africa [21]. In Brazil, the first reported case of Hansen's disease was in Rio de Janeiro in the 17th century [22]. It is reasonable to theorize that $M$. leprae was brought from Europe to Brazil and that, besides infecting other human beings, contaminated soil, water, and vegetation and, consequently, infected armadillos. Armadillos are uniquely susceptible to infection, harboring and multiplying the pathogen in their bodies and becoming an environmental source of the bacillus for humans. Eventually, when humans come into direct contact with the contaminated animal (or indirect contact via contaminated soil or water in the animal's habitat), they can become infected and develop Hansen's disease. People who develop the disease can multiply the bacillus and become a source of the bacteria for other individuals and the environment.

Although the 3 pillars of One Health—human, animal, and environmental-are evident in Brazil today in relation to Hansen's disease, it remains to determine the strength of evidence for zoonotic transmission of $M$. leprae from wild armadillos to people in communities where hunting, handling, butchering, and eating armadillos are commonplace.

\section{Zoonotic Hansen's disease in Brazil}

Persons affected by Hansen's disease in Brazil often report no known contact with another affected person, either in their household or outside. A study in Espírito Santo state from 2006 found that $55 \%$ of 506 patients had no known contact with infected individuals [23]. However, in the same group of patients, $68 \%$ reported direct contact (handling, butchering, or eating) with armadillos, compared with $48 \%$ of controls [24]. These data from Espírito Santo were combined in a recently published systematic review and meta-analysis with data from 2 other case-control studies, based in Ceará (2006) and Pará (2018), yielding a pooled odds ratio for Hansen's disease of 2.23 (95\% confidence interval [CI] 1.73, 2.88) comparing people who had direct armadillo contact with those in the same communities who did not have direct contact [25]. In the 3 studies, direct contact was defined as hunting or eating (Ceará); hunting, eating, or handling (Espírito Santo); and hunting (Pará, where it was noted that all cases who hunted also ate armadillo meat).

This systematic review found that the equivalent effect in the USA (also based on 3 casecontrol studies) was almost twice as high, with an odds ratio of 4.22 (95\% CI 2.34, 7.59). This higher relative risk probably reflects the much lower background risk from person-toperson transmission in a non-endemic country. Other findings included an apparent doseresponse relationship, from indirect contact (1.4-fold odds) to hunting armadillos (2.5-fold odds) [25].

The authors estimated that confounding and bias might reduce effect sizes by up to $40 \%$, meaning that the additional zoonotic risk of Hansen's disease for people in communities in Brazil where Hansen's disease is endemic and contact with armadillos is common would be approximately $34 \%$ higher (with a CI ranging from a very small additional risk to $73 \%$ higher odds). The exact proportion of people in these communities who have direct contact with armadillos is unknown, but $34 \%$ higher odds yield population attributable fractions (the proportion of all cases of Hansen's disease in the community attributable to contact with armadillos) of $3.3 \%$ ( 1 in 30 cases) if $10 \%$ of people have direct contact, 1 in 10 cases if $33 \%$ have direct contact, and 1 in 7 cases if half the people in the community have direct contact. 
In endemic communities where person-to-person spread is the main mode of transmission, the additional risk of zoonotic transmission was evident in a cross-sectional study which reported a higher median anti-phenolic glycolipid 1 (PGL-1) titer in people who consumed armadillo meat more than once per month compared with not at all [26] and in a study among child and adolescent household contacts of Hansen's disease cases which reported higher antinatural octyl disaccharide-leprosy IDRI diagnostic (NDO-LID) antibody levels in those who had consumed armadillo meat compared to those who had not [27].

\section{One Health and armadillos}

Armadillos are known to host a range of bacterial, fungal, protozoal, and other parasitic agents, including members of the genera Histoplasma, Coccidioides, Trypanosoma, Toxoplasma, Sarcocystis, Leptospira, Sporothrix, Leishmania, and Paracoccidioides [11,28,29]. Zoonotic transmission of these pathogens is unproven, but measures to reduce human contact with armadillos to prevent zoonotic transmission of $M$. leprae might reduce the incidence of other diseases.

Potentially zoonotic viral infections in armadillos have not been described, but this almost certainly reflects a lack of investigation.

Interestingly, armadillos serve as a food source for the triatomine bugs (Rhodnius prolixus) that are vectors of Trypanosoma cruzi, the causative agent of Chagas disease, and as a reservoir of T. cruzi [29]. It has recently been demonstrated by experimental oral infection that M. leprae remain viable in the gut of $R$. prolixus for up to 20 days, move along the digestive tract, and that $M$. leprae from triatomine bug feces can be inoculated successfully into mouse foot pads [30]. However, studies of transmission of $M$. leprae to humans via arthropod vectors are mostly dated, and this hypothetical route requires investigation using molecular methods [16].

The other important aspect of armadillos in Brazil from a One Health perspective is their ecosystem role, which includes pest control, seed dispersal, nutrient cycling, and earth moving (for the benefit of other species) [11]. Protection of armadillo species in Brazil whether as a public health measure to prevent zoonotic Hansen and other human diseases or simply to ensure the survival of an endangered animal has consequences for ecosystems and biodiversity, thereby cementing the third pillar of a One Health approach.

\section{Applying a One Health approach to public health policy in Brazil}

We have described the anomaly that is apparent in Hansen's disease being recognized as a zoonotic disease in the USA, a non-endemic country where few people have contact with wild armadillos, but not in Brazil, an endemic country where contact with armadillos is common. We accept the prime role of person-to-person transmission in sustaining Hansen's disease endemicity in Brazil, where the new case detection rate has not changed substantially over the past 10 years, from 20 new cases per 100,000 in 2009 to 14 per 100,000 in 2018 [10]. However, to ignore the contribution to Hansen's disease endemicity of environmental sources and zoonotic transmission of $M$. leprae is negligent. It is also inconsistent with any long-term ambition to eliminate the disease. WHO Global Hansen's Disease Strategy 2021-2030 stated that “eradication of [Hansen's disease] is not feasible at this point of time due to presence of a zoonotic reservoir in some areas" and that "studies to understand the mode of zoonotic transmission and its overall epidemiological significance will be needed" [31]. Eradication (rather than elimination) is almost certainly not feasible at any point in time for environmental and sylvatic mycobacteria. However, the mention of zoonotic transmission is a welcome addition to global Hansen's disease strategy, and we agree that research is needed, ideally directed from within endemic countries which have zoonotic reservoirs [32]. 
This research needs to be transdisciplinary, under the umbrella of One Health, encompassing social and anthropological research to understand community practices in relation to contact with wild armadillos [14], ecological studies in partnership with conservation groups to map and characterize transmission of $M$. leprae and its persistence within armadillos $[11,12,29]$, and genomic studies to determine the relatedness of $M$. leprae strains infecting humans and animals $[8,17]$. A better understanding of pathways to infection, including that these might not be from person to person, is also important in destigmatising disease. Brazil has not only ample scientific capacity to conduct such research and build the necessary evidence base [4], but is also well placed to collaborate with neighboring countries where zoonotic transmission presents a barrier to the elimination of Hansen's disease from endemic foci [32].

In the meantime, national programs to reduce endemicity and ultimately eliminate the disease from these countries should not ignore existing evidence for zoonotic transmission. From a One Health perspective, this approach is short sighted, both in terms of informing health professionals and the population about the risk of infection by $M$. leprae through contact with armadillos and in protecting the ecological richness of diverse and fragile ecosystems. The aim of this Viewpoint is to stimulate debate in Brazil, leading ultimately to a shift in public health policy. This is not a trivial task and will involve persuading many stakeholders including scientists and politicians. As a first step, we propose that public health authorities and medical associations in Brazil concerned with Hansen's disease give serious consideration to updating guidelines in accordance with a One Health approach and consistent with WHO Global Hansen's Disease Strategy 2021-2030.

\section{References}

1. Bidaisee S, Macpherson CN. Zoonoses and one health: a review of the literature. J Parasitol Res. 2014; 2014:874345. Epub 2014/03/19. https://doi.org/10.1155/2014/874345 PMID: 24634782; PubMed Central PMCID: PMC3928857.

2. Gruetzmacher K, Karesh WB, Amuasi JH, Arshad A, Farlow A, Gabrysch S, et al. The Berlin principles on one health-Bridging global health and conservation. Sci Total Environ. 2020:142919. Epub 2020/ 10/25. https://doi.org/10.1016/j.scitotenv.2020.142919 PMID: 33097250; PubMed Central PMCID: PMC7550087.

3. Laing G, Vigilato MAN, Cleaveland S, Thumbi SM, Blumberg L, Salahuddin N, et al. One Health for neglected tropical diseases. Trans R Soc Trop Med Hyg. 2020. Epub 2020/11/11. https://doi.org/10. 1093/trstmh/traa117 PMID: 33169163.

4. Gebreyes WA, Dupouy-Camet J, Newport MJ, Oliveira CJ, Schlesinger LS, Saif YM, et al. The global one health paradigm: challenges and opportunities for tackling infectious diseases at the human, animal, and environment interface in low-resource settings. PLoS Negl Trop Dis. 2014; 8(11):e3257. Epub 2014/11/14. https://doi.org/10.1371/journal.pntd.0003257 PMID: 25393303; PubMed Central PMCID: PMC4230840.

5. Storrs EE. The nine-banded armadillo: a model for leprosy and other biomedical research. Int J Lepr Other Mycobact Dis. 1971; 39(3):703-14. Epub 1971/07/01. PMID: 5169923.

6. Walsh GP, Meyers WM, Binford CH, Gerone PJ, Wolf RH, Leininger JR. Leprosy-a zoonosis. Lepr Rev. 1981; 52 Suppl 1:77-83. Epub 1981/12/01. https://doi.org/10.5935/0305-7518.19810060 PMID: 7339400.

7. Truman R. Leprosy in wild armadillos. Lepr Rev. 2005; 76(3):198-208. Epub 2005/10/27. PMID: 16248207.

8. Sharma R, Singh P, Loughry WJ, Lockhart JM, Inman WB, Duthie MS, et al. Zoonotic Leprosy in the Southeastern United States. Emerg Infect Dis. 2015; 21(12):2127-34. Epub 2015/11/20. https://doi. org/10.3201/eid2112.150501 PMID: 26583204; PubMed Central PMCID: PMC4672434.

9. Mohan S, Fairley JK. A Challenging Case of Domestically Acquired Leprosy in the Southern United States. Open Forum Infect Dis. 2020; 7(3). https://doi.org/10.1093/ofid/ofaa060 PMID: 32190708

10. Ministério da S. Boletim epidemiológico hanseníase 2020. 1a ed. Brasília: Ministério da Saúde, Secretaria de Vigilância em Saúde. Departamento de Doenças de Condições Crônicas e Infecções Sexualmente Transmissíveis; 2020 2020. 52 p. 
11. Rodrigues TF, Mantellatto AMB, Superina M, Chiarello AG. Ecosystem services provided by armadillos. Biol Rev Camb Philos Soc. 2019. Epub 2019/08/27. https://doi.org/10.1111/brv.12551 PMID: 31448491.

12. Deps $P$, Antunes JM, Santos AR, Collin SM. Prevalence of Mycobacterium leprae in armadillos in Brazil: A systematic review and meta-analysis. PLoS Negl Trop Dis. 2020; 14(3):e0008127. Epub 2020/03/ 24. https://doi.org/10.1371/journal.pntd.0008127 PMID: 32203502; PubMed Central PMCID: PMC7156091.

13. International Union for Conservation of Nature (IUCN). IUCN Red List of Threatened Species Cambridge, England: IUCN; 2020 [19/01/2021]. Available from: https://www.iucnredlist.org/.

14. Kerr L, Kendall C, Sousa CAB, Frota CC, Graham J, Rodrigues L, et al. Human-armadillo interaction in Ceara, Brazil: Potential for transmission of Mycobacterium leprae. Acta Trop. 2015; 152:74-9. Epub 2015/08/02. https://doi.org/10.1016/j.actatropica.2015.07.023 PMID: 26232656.

15. Currie DH. The Second International Conference on Leprosy, Held in Bergen, Norway. August 16 to 19 , 1909: Public Health Reports (1896-1970); 1909 17/09/1909. 6 p.

16. Ploemacher $T$, Faber WR, Menke H, Rutten V, Pieters $T$. Reservoirs and transmission routes of leprosy; A systematic review. PLoS Negl Trop Dis. 2020; 14(4):e0008276. Epub 2020/04/28. https://doi. org/10.1371/journal.pntd.0008276 PMID: 32339201; PubMed Central PMCID: PMC7205316.

17. Singh V, Turankar RP, Goel A. Real-time PCR-based quantitation of viable Mycobacterium leprae strain from clinical samples and environmental sources and its genotype in multi-case leprosy families of India. Eur J Clin Microbiol Infect Dis. 2020; 39(11):2045-55. Epub 2020/06/25. https://doi.org/10.1007/ s10096-020-03958-w PMID: 32577954.

18. Hockings KJ, Mubemba B, Avanzi C, Pleh K, Düx A, Bersacola E, et al. Leprosy in wild chimpanzees. bioRxiv. 2020:2020.11.10.374371. https://doi.org/10.1101/2020.11.10.374371

19. Vizcaíno SF, Loughry WJ. Xenarthran biology: past, present, and future. In: Vizcaíno SF, Loughry WJ, editors. The biology of the Xenarthra. Gainesville: University Press of Florida; 2008.

20. Goncalves VF, Stenderup J, Rodrigues-Carvalho C, Silva HP, Goncalves-Dornelas H, Liryo A, et al. Identification of Polynesian mtDNA haplogroups in remains of Botocudo Amerindians from Brazil. Proc Natl Acad Sci U S A. 2013; 110(16):6465-9. Epub 2013/04/12. https://doi.org/10.1073/pnas. 1217905110 PMID: 23576724; PubMed Central PMCID: PMC3631640.

21. Monot M, Honore N, Garnier T, Araoz R, Coppee JY, Lacroix C, et al. On the origin of leprosy. Science. 2005; 308(5724):1040-2. Epub 2005/05/17. https://doi.org/10.1126/science/1109759 PMID: 15894530.

22. Eidt LM. Breve história da hanseníase: sua expansão do mundo para as Américas, o Brasil e o Rio Grande do Sul e sua trajetória na saúde pública brasileira. Saúde e Sociedade. 2004; 13(2):76-88. https://doi.org/10.1590/s0104-12902004000200008

23. Deps PD, Guedes BV, Bucker Filho J, Andreatta MK, Marcari RS, Rodrigues LC. Characteristics of known leprosy contact in a high endemic area in Brazil. Lepr Rev. 2006; 77(1):34-40. Epub 2006/05/24. PMID: 16715688.

24. Deps PD, Alves BL, Gripp CG, Aragao RL, Guedes B, Filho JB, et al. Contact with armadillos increases the risk of leprosy in Brazil: a case control study. Indian J Dermatol Venereol Leprol. 2008; 74(4):33842. Epub 2008/09/18. https://doi.org/10.4103/0378-6323.42897 PMID: 18797053.

25. Deps $\mathrm{P}$, Antunes J, Collin SM. Zoonotic risk of Hansen's disease from community contact with wild armadillos: A systematic review and meta-analysis. Zoonoses Public Health. 2020. Epub 2020/11/24. https://doi.org/10.1111/zph.12783 PMID: 33226194.

26. da Silva MB, Portela JM, Li W, Jackson M, Gonzalez-Juarrero M, Hidalgo AS, et al. Evidence of zoonotic leprosy in Para, Brazilian Amazon, and risks associated with human contact or consumption of armadillos. PLoS Negl Trop Dis. 2018; 12(6):e0006532. Epub 2018/06/29. https://doi.org/10.1371/ journal.pntd.0006532 PMID: 29953440; PubMed Central PMCID: PMC6023134.

27. Serrano-Coll H, Mora HR, Beltran JC, Duthie MS, Cardona-Castro N. Social and environmental conditions related to Mycobacterium leprae infection in children and adolescents from three leprosy endemic regions of Colombia. BMC Infect Dis. 2019; 19(1):520. Epub 2019/06/15. https://doi.org/10.1186/ s12879-019-4120-2 PMID: 31196008; PubMed Central PMCID: PMC6567403.

28. Fernandes GF, Deps P, Tomimori-Yamashita J, Camargo ZP. IgM and IgG antibody response to Paracoccidioides brasiliensis in naturally infected wild armadillos (Dasypus novemcinctus). Med Mycol. 2004; 42(4):363-8. Epub 2004/10/12. https://doi.org/10.1080/13693780310001658748 PMID: 15473362.

29. Kluyber D, Desbiez ALJ, Attias N, Massocato GF, Gennari SM, Soares HS, et al. Zoonotic parasites infecting free-living armadillos from Brazil. Transbound Emerg Dis. 2020. Epub 2020/09/24. https://doi. org/10.1111/tbed.13839 PMID: 32964690. 
30. Neumann Ada S, Dias Fde A, Ferreira Jda S, Fontes AN, Rosa PS, Macedo RE, et al. Experimental Infection of Rhodnius prolixus (Hemiptera, Triatominae) with Mycobacterium leprae Indicates Potential for Leprosy Transmission. PLoS ONE. 2016; 11(5):e0156037. Epub 2016/05/21. https://doi.org/10. 1371/journal.pone.0156037 PMID: 27203082; PubMed Central PMCID: PMC4874629.

31. World Health Organization. Global consultation of National Leprosy Programme managers, partners and affected persons on Global Leprosy Strategy 2021-2030: Report of the virtual meeting 26-30 October 2020. New Delhi: 2020.

32. Schaub R, Avanzi C, Singh P, Paniz-Mondolfi A, Cardona-Castro N, Legua P, et al. Leprosy Transmission in Amazonian Countries: Current Status and Future Trends. Current Tropical Medicine Reports. 2020; 7(3):79-91. https://doi.org/10.1007/s40475-020-00206-1 